\title{
Ethics of Clinical Decision-Making for Older Drivers: Reporting Health-Related Driving Risk*
}

\author{
Barbara Mazer, 1,2 Maude Laliberté, ${ }^{3}$ Matthew Hunt, 1,2 Josée Lemoignan, ${ }^{3}$ Isabelle Gélinas, 1,2 \\ Brenda Vrklian, ${ }^{4}$ Gary Naglie, 5,6 and Shawn Marshall7
}

\begin{abstract}
RÉSUMÉ
Le vieillissement de la population engendre une augmentation du nombre de conducteurs âgés. Les professionnels de la santé ont la responsabilité de fournir des soins en préservant le secret professionnel tout en assurant la sécurité du public. Cet article traite de l'analyse éthique relative à la prise de décisions en lien avec le signalement aux autorités compétentes des conducteurs âgés identifiés comme étant à risque. Des considérations éthiques inhérentes au signalement des conducteurs à risque sont traitées, telles que l'autonomie, le secret professionnel, la relation thérapeutique et l'incertitude associée à l'évaluation de la conduite automobile. Nous abordons également la question de la responsabilité des divers agents moraux. L'incertitude entourant le raisonnement clinique et les concepts liés à l'évaluation du risque sont également traités. Enfin, nous présentons deux cas illustrant certains défis auxquels sont confrontés les professionnels de la santé dans l'atteinte d'un équilibre entre leurs responsabilités face à leurs patients et celles visant à assurer la sécurité du public.
\end{abstract}

\section{ABSTRACT}

The number of older drivers will continue to increase as the population ages. Health care professionals have the responsibility of providing care and maintaining confidentiality for their patients while ensuring public safety. This article discusses the ethics of clinical decision-making pertaining to reporting health-related driving risk of older drivers to licensing authorities. Ethical considerations inherent in reporting driving risk, including autonomy, confidentiality, therapeutic relationships, and the uncertainty about determining individual driving safety and risk, are discussed. We also address the moral agency of reporting health-related driving risk and raise the question of whose responsibility it is to report. Issues of uncertainty surrounding clinical reasoning and concepts related to risk assessment are also discussed. Finally, we present two case studies to illustrate some of the issues and challenges faced by health care professionals as they seek to balance their responsibilities for their patients while ensuring road safety for all citizens.

1 Faculty of Medicine, School of Physical and Occupational Therapy, McGill University

2 Centre de recherche interdisciplinaire en réadaptation du Montréal métropolitain (CRIR) - site Jewish Rehabilitation Hospital, Laval

3 Faculté de médecine, École de réadaptation, Université de Montréal, and Centre de recherche interdisciplinaire en réadaptation du Montréal métropolitain (CRIR)

4 School of Rehabilitation Science, McMaster University

5 Department of Medicine and Rotman Research Institute, Baycrest Health Sciences; Research Department, Toronto Rehabilitation Institute, University Health Network

6 Department of Medicine and Institute of Health Policy, Management and Evaluation, University of Toronto

7 Ottawa Hospital Research Institute, University of Ottawa

* The authors would like to thank the Research Teams of the CIHR Team in Driving in Older Persons (Candrive II) Research Program funded by Canadian Institutes of Health Research (CIHR) and the Professional Ethics in Rehabilitation Network (PERN). Maude Laliberté holds a doctoral fellowship from the Fonds de recherche du Québec-Santé (FRQ-S). Matthew Hunt is supported by a Chercheur Boursier (research scholar) award from the Fonds de recherche du Québec-Santé (FRQ-S). Gary Naglie is supported by the George, Margaret and Gary Hunt Family Chair in Geriatric Medicine, University of Toronto.

Manuscript received: / manuscrit reçu : 26/06/14

Manuscript accepted: / manuscrit accepté : 02/03/15

Mots clés : vieillissement, conduite automobile, évaluation, éthique clinique

Keywords: aging, driving, assessment, clinical ethics 
La correspondance et les demandes de tirés-à-part doivent être adressées à: / Correspondence and requests for offprints should be sent to:

Barbara Mazer, Ph.D.

CRIR-Jewish Rehabilitation Hospital

3205 Place Alton Goldbloom

Laval, QC H7V 1R2

(barbara.mazer@mcgill.ca)

In 2009, 3.25 million (75\%) Canadians aged 65 and older possessed a driving licence (Turcotte, 2012). With the aging of the population and the increasing proportion of drivers in this cohort, especially female drivers, this number is expected to rise considerably (Turcotte, 2012). The majority of older Canadians use their car as their primary mode of transportation (Turcotte, 2012; Newbold, Scott, Spinney, Kanaroglou, \& Paez, 2005). Although the rate of crashes per kilometer driven in the age 70 and older age group is higher compared to younger age groups (Li, Braver, \& Chen, 2003), many older drivers are aware of age-related changes that can affect their safety behind the wheel and adapt their driving to compensate for any decrease in skills. They make fewer and shorter trips (Newbold et al., 2005), and avoid driving during peak periods (Scott et al., 2009), at night (Fain, 2003), and in poor weather conditions (Myers, Trang, \& Crizzle, 2011). Also, driving is an overlearned task, and older drivers with many years of driving experience have developed automatic driving skills and behaviors that may help maintain driving safety (Fain, 2003).

On the other hand, many illnesses and disabilities can compromise a person's ability to drive safely, and typically, these conditions are more prevalent in the older population of drivers. For example, it is known that 28 per cent of Canadians aged 65 and older who have received a diagnosis of dementia maintain a driving licence (Turcotte, 2012). Irrespective of the rate of crashes for older drivers, their mortality rate following a crash is increased. This is due in part to frailty, but does not increase risk for other users ( $\mathrm{Li}$ et al., 2003; Eberhard, 2008). Although a large increase in the number of crashes by older drivers has been projected (Marshall, 2008), in reality, according to the Insurance Institute for Highway Safety, these rates now seem to be decreasing (Insurance Institute for Highway Safety [IIHS], 2008, 2014).

Facts such as these are important to consider as the discussion around determining fitness to drive arises from the assumption that older people are significantly more likely to crash compared to other age groups (Fain, 2003). There is much evidence to consider when determining how and if older drivers' safety should receive special attention, such as the accuracy of projections that are based on earlier cohorts when women were less likely to drive (Sivak, 2013) and older individuals may have been less healthy, as well as the fact that older drivers are at increased risk of fatal crashes due to their frailty (Statistics Canada, 2008).

Most Canadians depend on their car for conducting their daily activities and participating in their life roles (Turcotte, 2012). Driving a car offers independence, especially in older adults (Dickerson et al., 2007), and is directly linked to a high quality of life (Oxley \& Whelan, 2008). It allows older individuals to stay in their homes as it facilitates independence in activities of daily living and community life (Fain, 2003). Revoking an individual's license may result in social isolation, decreased participation in activities that they value, challenges for accomplishing basic activities such as grocery shopping, increased dependence on others (Fain, 2003; Ragland, Satariano, \& MacLeod, 2005; Marottoli et al., 2000), and depression. Driving also holds an important symbolic value that relates to identity and a sense of freedom (Lord, Despres, \& Ramadier, 2011). Additionally, public transport is not equally accessible in all Canadian regions and can be particularly expensive, difficult to use, or even dangerous (Organisation for Economic Co-operation Development [OECD], 2001) for individuals with low mobility or endurance (Lord et al., 2011).

It is critical to recognize the instrumental and symbolic importance of possessing a driver's license, and the harm associated with either preventing safe drivers from driving or permitting unsafe drivers to continue to drive. This complex situation underscores the importance of effective regulations and accurate screening of those at greatest risk in order to distinguish safe from unsafe drivers. Society has a vested interest in addressing the safety of older drivers, especially when faced with news stories of crashes caused by older drivers with poor driving skills. Such reports include events such as an older driver pressing the accelerator and hitting pedestrians (Murdock, 2014) as well as a population survey reporting public anxiety regarding older drivers (CBC News, 2014). However, the pertinent issue is not the age of the driver; rather, it is the impact of medical conditions and medications affecting sensory, physical, and cognitive functioning that in turn may impact an individual's driving skills and contribute to crashes. It is important that any decision-making 
concerning driving is based on the best available evidence, not ageism.

Determining and reporting a medically at-risk driver to licensing authorities is a mechanism to protect the driver in question as well as society from the potential harm that could be incurred if that driver were involved in a collision. Health care professionals (HCP) have an essential role in this process as they have privileged patient information. Reporting a driver is a key example of a situation where HCPs must balance their primary responsibility for the health and well-being of their patient (including promoting autonomy and maintaining confidentiality of the patient's information), with protecting the public in terms of road safety. Such scenarios highlight the so-called "dual responsibility" of HCPs. Not only does unsafe driving place the patient at risk, but there is also a potential increased risk for others, including passengers in the patient's car, pedestrians, cyclists, and other motorists. Determining how to respond to the responsibility of supporting the common good (through action to protect or minimize risk or harm to third parties) while ensuring that their primary obligation to provide the best care possible for their individual patients is maintained can be a vexing issue for HCPs.

In this article, we discuss the ethics of clinical decisionmaking around the reporting of older drivers because of potential medical risk. Codes of ethics can provide guidance to HCPs. HCPs need to conduct a careful analysis of each situation in order to ensure they take the right course of action when faced with an ethical dilemma, such as reporting a patient who is suspected of being an unsafe driver. First, we review regulatory factors, such as laws and policies that are critical to understanding HCP obligations in particular settings. Second, we address the moral agency of reporting individuals where medical fitness to drive has been questioned. We ask who is responsible to report and for whom, and discuss the uncertainty surrounding the clinical reasoning of reporting driving risk and concepts related to risk assessment. We then review ethical considerations linked to the reporting of driving risk, including confidentiality, therapeutic relationships, risky choices, and safety issues. Finally, we present two case studies that illustrate some of the issues and challenges faced by HCPs as they seek to balance their responsibilities towards their patients with ensuring road safety for all citizens.

\section{Regulatory Landscape}

In Canada, regulations governing licensing of drivers are a provincial responsibility, and therefore procedures differ from province to province. There are differences in the required steps that drivers must undergo as they age (e.g., medical evaluation, written test, refresher course), as well as the obligations of different HCPs regarding the reporting of a patient's health-related driving risk. Broadly speaking, there are three different legal standards for reporting driving risk that have been adopted across Canada. First, in various jurisdictions, different HCPs must report individuals - who they judge to be at heightened driving risk - to the relevant government agency. This type of reporting is a mandatory reporting system. In this system, the HCP is protected from legal liability for making such a report; however, HCPs may be held responsible for failing to report. In Canada, 10 of the 13 provinces and territories (all except Alberta, Québec, and Nova Scotia) have a mandatory reporting system in place (Solomon, Chamberlin, \& Chiodo, 2011; Canadian Medical Association [CMA], 2012).

A second type of standard exists in which there is no legally mandated requirement for reporting healthrelated driving risk. In the only jurisdiction in Canada, Alberta, with a no-obligation reporting system (Solomon et al., 2011; Canadian Medical Association [CMA], 2012), HCPs are not required to report patients they deem to be a driving risk. Finally, in Québec and Nova Scotia there is discretionary reporting for health-related driving risk (Solomon et al., 2011; Canadian Medical Association [CMA], 2012). Under this system, HCPs may report a driver to the relevant agency but are not obligated to do so. When making such a report, they are authorized to report only the information relevant to the driving risk, and if they do report, they are protected from legal liability.

In the province of Quebec, for example, the Highway Safety Code states that "a health professional may, according to his field of practice, report to the Société [licensing authority] the name, address and state of health of a person 14 years of age or older whom he considers unfit to drive a road vehicle having regard, in particular, to the illnesses, deficiencies and situations incompatible with the driving of a road vehicle [...]." (Société de l'assurance automobile du Québec [SAAQ], 2014, section 603). This is a permissive or discretionary system for driver reporting that may apply to an HCP from any discipline. Under such a system, HCPs cannot be sued for reporting a patient whom they judge to be a driving risk; however, he or she may still be held accountable by their professional regulatory board if they fail to act in a professional manner when reporting a patient's driving to the relevant authority. For example, HCPs would be considered in breach of their professional duties if they reported driving risk in reprisal against a patient, or if they did so in a deliberately discriminatory fashion. Furthermore, under such a system, the reporting does not require prior authorization from the patient and may 
be done without his or her being informed, although HCPs may consider it appropriate to obtain permission beforehand.

Although the specific reporting requirements may differ across the jurisdictions, with all three legal approaches the HCP is only one source of information. Ultimately, the final decision regarding driving status is made by the provincial licensing authority. While it is possible to debate the pros and cons of these systems (Appel, 2009), such a discussion is outside the scope of this article. Although mandatory reporting legislation presents similar ethical dilemmas, a discretionary reporting system is likely to cause HCPs the greatest uncertainty in determining how to respond when they suspect that their client presents a health-related driving risk. HCPs under any reporting system may struggle with how to evaluate a patient's level of driving risk, to themselves as well as to others. However, in making a determination of whether to report, HCPs must consider potential risks that may result from reporting, such as disregard for their autonomous choice, breach of the therapeutic alliance, and diminished trust.

\section{Addressing Ethical Considerations of Clinical Decision-Making}

Many ethical considerations are associated with clinical decision-making about whether to report the medically at-risk driver with a health-related driving risk. HCPs are committed to helping their patients (beneficence), as well as to prevent or mitigate harm (nonmaleficence). Professional codes of ethics and laws also direct HCPs to respect their patients' informed choices (autonomy). Sometimes when HCPs care for patients, they find that these three principles conflict; consequently, HCPs must weigh them carefully to determine the best course of action. When an HCP suspects that a patient is at high risk of causing a motor vehicle collision yet that patient continues to drive and opposes the HCP's sharing this concern with the authorities, how should the $\mathrm{HCP}$ proceed? In what instances are there compelling reasons to report a patient despite their objection? In the following discussion, we review key ethical considerations associated with making such decisions.

\section{Moral Agency and Reporting Driving Risk}

Who has the responsibility to determine and report potentially dangerous drivers? Decisions regarding driving safety can be made at three levels (see Figure 1). The first level refers to regulations (policies) that dictate a compulsory reporting of any change in a person's health condition regardless of age as well as a broad screening at the population level at specific ages. For example, in the province of Quebec, the highway safety code

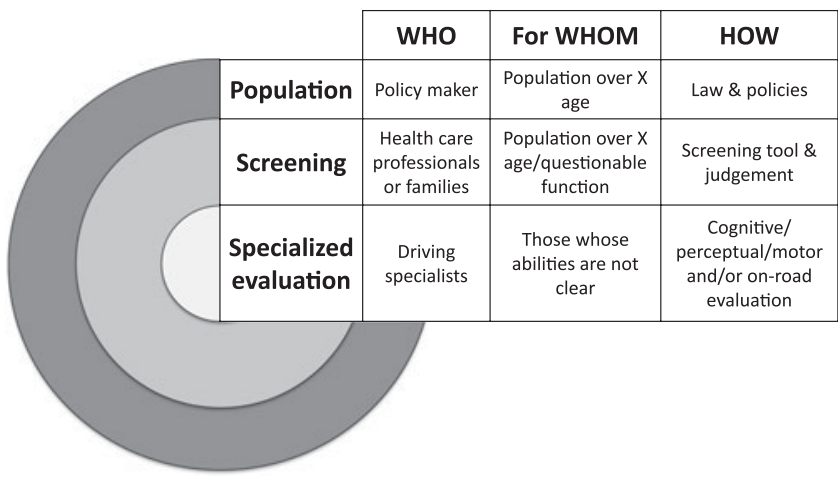

Figure 1: Levels of determining driving safety in older drivers

states that a "visual acuity of less than $6 / 15$ with both eyes open and examined together is essentially inconsistent with driving a road vehicle" (SAAQ, Statutes of Quebec, 2014). In Ontario, at age 80 and older, specific requirements apply which are different than for younger drivers. The Ontario Ministry of Transportation states "If you are 80 years or older, you are required to renew your driver's licence every two years [....] You need to undergo a driving-record review, complete a vision test and participate in a 45-minute group education session, followed by an in-class screening component" (Ontario Ministry of Transportation, 2013).

The second level of reporting responsibility entails HCPs (e.g., physician, nurse, occupational therapist) screening a patient for impairments that may impact driving safety either when providing intervention for a medical condition directly related to driving skills (e.g., dementia, stroke, Parkinson's disease) or for another purpose (e.g., annual medical check-up, new glasses). Following this screening, the HCP must determine how to proceed: doing nothing further, reporting the patient to the authorities, or referring him or her for further testing. In medical clinics where clients are seen by a multidisciplinary team, the responsibility to report can be shared among HCPs, whereas in other circumstances, it is solely the responsibility of specific HCPs depending on the jurisdiction. Although in many instances the HCPs do in fact have this responsibility, one study found that few physicians state that they should be responsible (Sims, Rouse-Watson, Schattner, Beveridge, \& Jones, 2012).

The third level of evaluation for purposes of reporting pertains to specialized driving assessment. This evaluation is conducted by an HCP, typically an occupational therapist, who has received specialized training in how to assess driving performance and safety. The evaluation procedures often include office-based testing of cognitive, perceptual, and motor abilities using paperand-pencil tasks and/or driving-specific computerized assessments, as well as a behind-the-wheel evaluation. 
During the on-road portion, functional driving behaviors and skills are assessed. These evaluations usually result from a direct request from the driving licensing agency after it has been informed that the individual in question may be at risk behind the wheel due to healthrelated changes or from referrals from other HCPs.

Decisions about reporting a medically at-risk driver have important ethical ramifications, which may differ according to these three levels. At the population level, a major concern relates to issues of justice, where only a subgroup of the population is targeted (e.g., older adults) rather than aiming at specific individuals of all ages based on some indication of their ability to drive such as a specific, diagnosed medical condition. However, at this level, the involvement of HCPs is clearly guided by legislation.

At the screening level, reporting an individual for questionable driving ability can negatively affect the therapeutic relationship. The therapeutic relationship between HCPs and patients is built upon trust, which is a key element for successful care and treatment. When an HCP identifies and reports a patient's driving risk despite the patient's objections, the therapeutic alliance may be strained or broken. Such an outcome can have serious repercussions. There is also the possibility that societal risks may accrue if patients fear having their driving risk reported to authorities. In turn, they may avoid visiting their physician for specific medical conditions for fear of being told they can no longer drive. In such situations, there is no opportunity for HCPs to work with their patients to minimize risks and find alternative strategies. If individuals avoid medical visits due to fear of having their driving risk identified and reported, their overall health and well-being could be jeopardized.

At the level of specialized evaluation, the outcome of an expert evaluator's (HCP's) inaccurate (or even accurate) decision can have a dramatic impact, either for not reporting unsafe driving or for revoking a license from a patient who has a low risk of crashes. Important overall issues to consider include determining (a) if each of these three levels is based on evidence and is applied fairly across all members of the community, (b) who has the expertise to make these decisions, and (c) if they have the appropriate tools to do so. Although important ethical considerations and implications exist at all three levels of determination, this article focuses on the role of HCPs in screening and evaluating patients for driving safety.

\section{Autonomy, Confidentiality, and the Therapeutic Relationship}

Autonomous choice is a central democratic right. A clinical interaction promotes an exchange process between the patient and his/her HCP where the goal is for the patient to be a partner in the decision-making process. Confidentiality is at the root of the therapeutic relationship by creating the necessary trust for the patient to engage and reveal information, knowing that this information will only be used for his or her benefit.

Confidentiality is based on privacy rights; however, this right is not absolute. HCPs can reveal confidential information if the patient agrees to the breach or if there is a compelling legally sanctioned reason to disclose confidential information to a third party, such as a driving authority. In general, the threshold for a breach of confidentiality is potentially higher in jurisdictions that do provide liability protection. A breach in this regard will be justified when there is a clear, imminent, and significant risk of harm to identifiable third parties that cannot otherwise be managed without disclosure of confidential information. In certain cases, there is a possibility that driving risk could reach this threshold. Revealing information without first informing the patient, even if allowed by the law, will likely disrupt the therapeutic alliance and may lead to harm. Careful attention should also be given to who else might be included in the decision-making process to support the patient in making choices that are consistent with their values and sense of personal integrity (Hunt \& Ells, 2011). If the HCP wishes to include the patient's family or others, consent needs to be obtained prior to sharing confidential information with them. Also, the consequences of a breach of confidentiality must be considered. Are the consequences more beneficial than the risk of breaking the therapeutic alliance, both now and in future health care interactions? If an HCP must break confidentiality, how can the risk threshold effectively be lowered as well as the potential for harm?

\section{Uncertainty and Reporting Driving Risk}

When HCPs strongly suspect that a patient is unable to drive safely and should be reported to the licensing authorities, cognitive, perceptual, and motor screening tools are available for HCPs' use to inform clinical decision-making concerning driving risk. However, there is no gold standard or evidence-based screening tools for assessing fitness to drive (Hoggarth, Innes, Dalrymple-Alford, \& Jones, 2013a, 2013b; Hopewell, 2002; Fitten, 2003). Although many screening tools are used in clinical practice for this purpose, the relationship between the functional ability to drive and test performance has yet to be established.

Several articles have reported on extensive reviews of off-road screening and evaluation tools and concluded that no single off-road test exists for predicting on-road performance (Vrkljan, McGrath, \& Letts, 2011; 
Kay, Bundy, Clemson, Cheal, \& Glendenning, 2012; Asimakopulos et al., 2012; Unsworth, Lovell, Terrington, \& Thomas, 2005). Vrkljan et al. (2011) reviewed the psychometric properties of clinical tools used for evaluating driving ability and found that measures currently in use lack adequate reliability and validity. This is complicated by the fact that best practices may differ depending on the clinical context and the range of diagnoses and impairments. Some evidence is emerging to begin the complex task of identifying the most accurate approach to screen for safe driving. Asimakopulos et al. (2012), for example, reviewed 52 measures of executive function and cognition and created the Driving Executive Function Tool Guide which provides useful information on each measure in relation to driving. The American Academy of Neurology's systematic review of the literature on the evaluation and management of driving risk in dementia (Iverson et al., 2010) provides some evidence for the usefulness of clinical tools. Also, in the ideal situation, these tools would not only need to have concurrent validity (i.e., be accurately related to actual on-road driving), but would also need to have predictive validity of future driving performance (i.e., crashes in the future).

A comprehensive screening tool is needed to accurately measure the various types of impairment that may affect driving performance (e.g., personality tests to identify impulsivity, cognitive testing, divided attention testing, vision and hearing testing, upper and lower limb motor and sensory testing). For example, the Assessment of Driving-Related Skills (ADReS) is a screening test recommended by the American Medical Association (AMA) to identify potentially unsafe older drivers with or without cognitive problems. However, the ADReS is limited in its ability to screen for individuals who are unsafe and present insufficient evidence to indicate who is safe to drive (Ott et al., 2013). Another recent study followed 279 older drivers with diagnosed or suspected dementia (Hoggarth et al., 2013b). The authors applied a logistic regression model including sensory-motor and cognitive tests to accurately predict pass or fail on a road test for 76 per cent of the sample. The authors concluded that off-road measures are not sufficiently accurate to determine on-road safety in older drivers with cognitive impairment. Although studies have evaluated both individual measures and different combinations of assessment tools, a comprehensive reliable and valid evaluation approach has not yet been established.

Despite on-road evaluation being considered the "gold standard" outcome for screening of driving-related skills, the accuracy of this approach has been questioned. In one study, researchers followed 56 drivers aged 70 and older with no cognitive or neurological impairment after completing a road test and found no significant increase in the odds of a motor vehicle crash over two years by those who failed the road test compared to those who passed (Hoggarth et al., 2013a). It is quite apparent that the accuracy and predictability of current approaches to screening and testing for fitness to drive may not be sufficiently accurate to determine who is safe and unsafe to drive. This uncertainty likely contributes to $\mathrm{HCPs}$ ' discomfort with reporting at-risk drivers.

A person's awareness or ability to perceive one's limitations (Marottoli \& Richardson, 1998) relates to their ability to understand the nature and degree of their functional impairments and to evaluate its impact (Pachana \& Patriwskyi, 2006; Sohlberg, 2000). Those individuals with an accurate awareness of their driving abilities have the potential to modify their driving and thus to decrease their risk exposure (Anstey, Wood, Lord, \& Walker, 2005), in contrast to those with limited awareness who may continue to drive in risky situations despite a decrease in functioning.

\section{Risk Assessment}

Assessing health-related driving risk is often difficult for HCPs. Their degree of confidence in the assessment of risk is variable without on-road testing. Are risks measured through the individual perspective or based on evidence-based information? In some cases, specific illnesses or injuries may result in clear driving risks (e.g., narcolepsy, hemianopsia, seizure disorders), and laws usually address these conditions. In other situations, there may be considerable uncertainty regarding driving risk.

Risk assessment has three distinct components: identification, estimation, and evaluation (Beauchamp \& Childress, 2009). Risk identification involves localizing a potential source of harm. An HCP may identify a driving risk related to a patient's health condition and/or functional status. The second component, risk estimation, entails an assessment of how likely it is that harm will occur and the expected severity of this outcome. In practice, an HCP estimates the likelihood and potential gravity of a driving risk based on available information, as well as estimating the degree of confidence in this evaluation. The third component, risk evaluation, requires weighing a risk in relation to other obligations, objectives, and values. Thus, an HCP may consider the driving risk in relation to competing obligations and responsibilities. Evaluation of a risk often differs, sometimes significantly, between HCPs based on diverse factors including their prior experience, personality, professional identity and commitments, and expertise.

Divergence regarding risk perception relating to the situation is thus an important concern to raise with patients. 
To exemplify the ethical dilemmas in this area of practice, we next present two cases. These are not intended to provide a definitive approach and decision, but rather to illustrate how ethical principles can be used to guide a thorough reflection of the situation and influence ethical decision-making.

\section{Clinical Cases}

\section{A Patient with Parkinson's Disease Who Had a Recent Fall: The Case of Mr. Lewis}

Mr. Lewis is a 72-year-old man who was referred to outpatient rehabilitation services following a total hip replacement. The injury had occurred when Mr. Lewis fell down the stairs outside his house. During the admission interview, Mr. Lewis disclosed that he has Parkinson's disease, which had been diagnosed two years prior to the fall. The physiotherapist is concerned that the effects of Mr. Lewis' Parkinson's disease could compromise his ability to drive safely. When she expresses her concern, Mr. Lewis insists that he is a safe and cautious driver. Following the interview, the physiotherapist remains uncomfortable with the situation. When she reviews the notes from the referring physician, she learns that the orthopaedic surgeon was under the impression that the patient had ceased to drive. No return appointment is planned with the orthopaedic surgeon. Mr. Lewis has a family doctor. The physiotherapist is uncertain about her clinical responsibilities of reporting the patient in this situation. Mr. Lewis is receiving services in a jurisdiction where there is a discretionary (non-mandatory but protected) system for reporting.

\section{Things to Consider}

Parkinson's disease is associated with motor, cognitive, and psychomotor dysfunction, which vary with individuals and stage of the disease (Heikkila, Turkka, Korpelainen, Kallanranta, \& Summala, 1998). It is unclear how these impairments, severity, or duration affect the ability to drive, as the literature on the subject is incomplete and contradictory (Schrag, 2005). One study found that patients with Parkinson's disease were significantly impaired on a road evaluation when placed in unfamiliar driving situations (Wood, Worringham, Kerr, Mallon, \& Silburn, 2005). Also, it is known that the dopaminergic drug that most patients take, Levodopa, can lead to the sudden onset of intense sleepiness (Frucht, Rogers, Greene, Gordon, \& Fahn, 1999). Furthermore, the clinical situation in which the physiotherapist may also help guide the procedure to be followed must be considered. If the therapist is working within a team, concern regarding driving safety may be discussed at a team meeting or another HCP may be the more appropriate person to handle the issue.

\section{Ethical Analysis}

The therapeutic relationship between Mr. Lewis and the physiotherapist in question is very important because he needs to be followed closely for his Parkinson's disease and for rehabilitation following his hip replacement. Moreover, the physiotherapist must also evaluate his risk of falls. In terms of addressing the concern regarding driving safety, the physiotherapist should ensure that all measures are implemented to manage the problem prior to breaching confidentiality. For example, she could educate Mr. Lewis about the potential driving risk and his legal obligation to inform the licensing agency of the change in his medical condition. She may raise her concerns with Mr. Lewis and ask his permission to discuss this with his family doctor. She should seek to persuade Mr. Lewis to allow her to disclose the pertinent information to the appropriate person who can act on it and may also help him find alternative transportation solutions (e.g., taxi, adapted transport, traveling with friends or family, ride programs offered by community agencies). If Mr. Lewis refuses the disclosure of information and does not want to consider alternative solutions, then the physiotherapist must decide: Should she respect Mr. Lewis's refusal and preserve the therapeutic relationship, or should she breach his confidentiality to protect his and the public's safety?

\section{Action Plan}

Although Mr. Lewis's physiotherapist might initially decide to signal her concerns (with or without informing her patient) about his driving to the government agency responsible for driving safety, she should carefully consider alternative steps first. The fact that Mr. Lewis did not report his driving behaviour to the orthopaedic surgeon may make the HCP more sceptical as to whether Mr. Lewis has been forthcoming about his medical condition to the referring physician; therefore, she should consider what possible avenues exist for addressing this issue. Also, there is some evidence that physician specialists may actually overestimate the driving ability of their patients. One study of neurologists found that they overestimated the ability to drive, such that 35 per cent of those who were approved to drive by their neurologist were unable to drive on the basis of an on-road driving test (Heikkila et al., 1998). The physiotherapist in this case, however, should also acknowledge her lack of certainty in evaluating driving risk related to Parkinson's disease, in general, and for Mr. Lewis, specifically. Ultimately, the risk presented by her patient might be sufficient to warrant the $\mathrm{HCP}^{\prime}$ 's reporting of potential unsafe driving or referring for further evaluation, but the physiotherapist should at a minimum be transparent 
with her patient and take steps to try to better estimate the degree of risk, and to get input from other HCPs who follow this patient, subject to the patient's consent to authorize such communication. The legislative system may influence the weighing of information and ultimate decision-making regarding reporting.

\section{Home Visit for Fall Assessment: The Case of Mrs. Smith}

A request for a home evaluation for 84-year-old Mrs. Smith has been made to the local home care nurse by her family doctor. The referral requests blood pressure monitoring following a recent transient ischemic attack, assessment for decreased balance, and assessment of the safety of the home environment. When the nurse arrives at the home, he notices small dents on both front fenders of the car parked in the driveway. During the interview and home assessment, the nurse is concerned that Mrs. Smith appears to have mild cognitive impairment and he decides to administer the Mini-Mental State Examination. Mrs. Smith's daughter is present during the visit, but when she begins talking about her mother's poor driving, Mrs. Smith tells her that she drives carefully, obeys all the rules, has never had a collision, and that she should stop and not talk about her driving with the nurse.

\section{Things to Consider}

Mild cognitive impairment (MCI) is a condition that affects cognitive functioning - usually memory, but at times non-memory domains such as executive performance. In MCI, the mild impairments in cognition do not affect daily functioning. There are several issues that need to be considered related to addressing patients with this condition. Has a diagnosis of MCI been made and if so, by whom? In considering how to proceed with the issue of driving, the nurse also must think about the possibility of disease progression, as not all individuals with this diagnosis progress to a diagnosis of dementia. Also, it is important to consider a patient's other medical conditions that may affect concerns of driving safety.

It is imperative to focus on the issues related to the quality of the information that is used in decisionmaking. The cause of the damage seen on the car is not self-explanatory. If this were used as a possible sign of unsafe driving, then the HCP must be sure that it occurred as a result of one or more at-fault collisions when Mrs. Smith was the driver, then (a) get a history of driving collisions/citations, (b) determine when the collision(s) occurred, and (c) confirm that it did not happen while parked in a parking lot or due to another person's driving error. It is also crucial for the HCP to consider the quality of measurement tools that are used to determine unsafe driving; specifically the predictability of the cognitive measure that was administered, and the evidence that the tools are associated with driving outcomes at an individual level.

\section{Ethical Analysis}

A key component of this case is the possibility that respecting Mrs. Smith's desire to conceal information from the nurse may put her at direct risk if unsafe driving is not detected. On the other hand, if her wishes are not respected, she may be placed at indirect risk if the trust in her daughter or treating team is undermined to the point where she turns away from them. The nurse must determine if the possible driving risks are imminent and serious enough to go against Mrs. Smith's autonomous choice not to discuss the issue. The trust between Mrs. Smith and the nurse is fragile, and the therapeutic relationship not well established yet. The driving risks are important enough for the nurse to be concerned, but are likely not imminent enough to justify not respecting Mrs. Smith's autonomous refusal. Also, the method of communicating information with the patient and their family is also an important consideration as communication can greatly influence the response of the individual; it can serve to preserve the professional relationship and also increase the likelihood that recommendations are carried out. Family members often contribute important information to the discussion surrounding their family member's driving safety; however, it is important that this be considered one of several possible sources of data. Family members almost always have the patient's best interests in mind, but this may lead them to be either overly cautious in their assessment of risk or to minimize the risk to enable independence or avoid conflict.

\section{Action Plan}

The home health nurse has limited and possibly contradictory information upon which to proceed. The ideal scenario would be for the nurse to try to convince Mrs. Smith to discuss this situation directly with her family physician. However, if, after the nurse discusses it with Mrs. Smith, she still does not change her mind, the nurse should respect her wishes and aim to improve the therapeutic relationship while gathering more information to better assess the driving risk. In all circumstances, it is crucial that the nurse communicate with the patient and, ideally, the family (with consent) to share his concerns and explain his responsibilities and possible courses of action. The nurse can also communicate potential modifications that may be implemented which are known to reduce risk and may help compensate for any declining skills. However, to involve the family, the nurse needs explicit consent from Mrs. Smith. In this case, we have a strong indication to the contrary. It is important to include the 
patient in the discussion about potential risk, assess their judgement and decision-making abilities, and provide resources and encourage them to seek further evaluation on their own. Potential resources that can be accessed include discussing the concern with the patient's family physician and / or referring to a driving specialist for further evaluation.

In such situations, it is essential to be open and transparent with the patient, always informing them of what steps will be taken and why, in order to maintain the therapeutic link and minimize the harm that could result from a break in the relationship (e.g., lack of medical monitoring and access to home services to ensure home safety). Through the development of a trusting relationship, options may be presented over time, allowing the nurse to better assess the patient's abilities, self-awareness, and judgement. Also, discussing the issue of driving at an early stage in the disease provides time for Mrs. Smith, her family, and her HCPs to plan for driving alternatives before safety becomes a major concern. A decline in functioning may occur, and beginning the discussion in advance can help facilitate the transition to driving cessation and mobilize resources for alternative modes of transportation. With this therapeutic alliance, the potential for the patient to adjust to possible changes and comply with recommendations is increased.

\section{Tools for Health Care Professionals}

The contextual factors surrounding HCPs' work have an impact on the approach to driving assessment and reporting. For example, access to a multidisciplinary team or specialized resources can provide support and assist with clinical decision-making and may dictate the appropriate procedures within that work environment. Also, the process may differ whether the HCP is mandated to provide a one-time assessment or is engaged in a long-term professional relationship with the patient. Once a patient has been screened for driving, organisational policies and the location of the service (i.e., private or public sector) could influence the follow-up that they receive. In the public health system in Canada, accessibility to services is limited by long wait times, whereas costs may restrict access to service in the private sector. The following list of questions can be considered by an HCP when evaluating whether to report a medically at-risk driver:

\footnotetext{
1. Are there other resources available to support decisionmaking, enrich the discussion, and provide alternative options?

2. Considering the type and quality of my relationship with the patient, how would my actions affect my professional relationship with him or her?
}

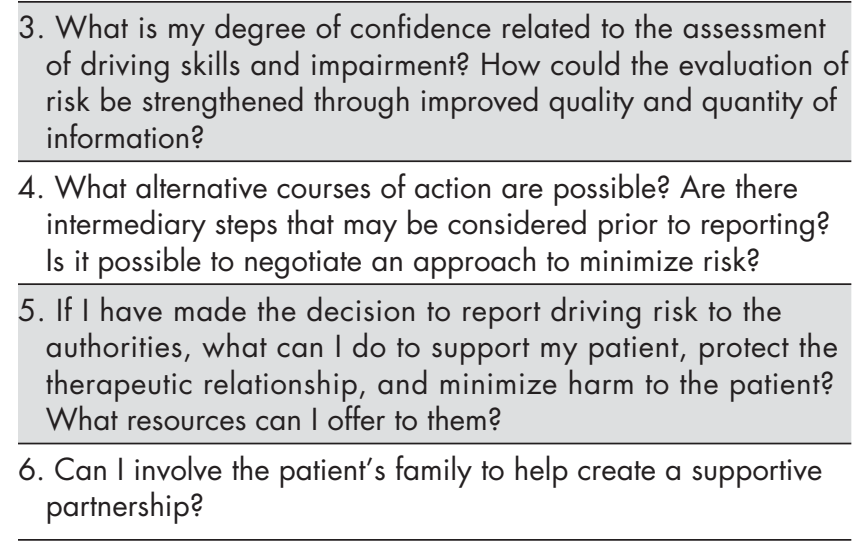

Each situation requires the HCP to conduct a careful analysis to ensure that the actions undertaken best balance respect for patient autonomy while ensuring safety for all. The clinical ethics committee of the Jewish Rehabilitation Hospital, a Montreal-based rehabilitation center, developed a web-based tool that can be used to guide $\mathrm{HCP}^{\prime} \mathrm{s}$ deliberations in these difficult driving-related situations (see Figure 2 for a simplified chart).

The detailed tool provides guidance to HCPs on various elements that should be considered when reflecting on reporting health-related driving risk. The tool also directs the HCP to literature and legislation from Quebec pertinent to the topic of discretionary reporting of driving risk. Finally, it suggests various elements to consider when an HCP estimates risk and provides ways to minimize the possible harm resulting from such situations. It is available in both French (http:/ / cmapspublic2.ihmc.us/rid=1LPFVVV0M-1WXL9SD1P9N/13\%20avril\%202013.cmap) and English (http:/ / cmapspublic2.ihmc.us/rid=1M66P2G6Q-1X374VC1TWD/3\%20sept\%202013.cmap).

Additional resources for driving-related information for older drivers can also be found at both the Alzheimer Society of Canada website (http://www.alzheimer. ca/en/About-dementia/For-health-care-professionals/ Driving) and the Candrive website (https://www. candrive.ca/index.php?option $=$ com_content\&task $=\&$ view=section\&id=3\&Itemid=34\&lang=en).

\section{Discussion: Navigating Reporting of Health-Related Driving Risk}

A clear challenge in addressing the issue of driving safety in a potentially high-risk group is to balance maintaining the autonomy of an individual while ensuring road safety for all citizens. To achieve this goal, HCPs must ensure that their decision-making process for reporting health-related driving risk is sound, nondiscriminatory with regard to age, and evidence-based inasmuch as the current level of evidence permits. 


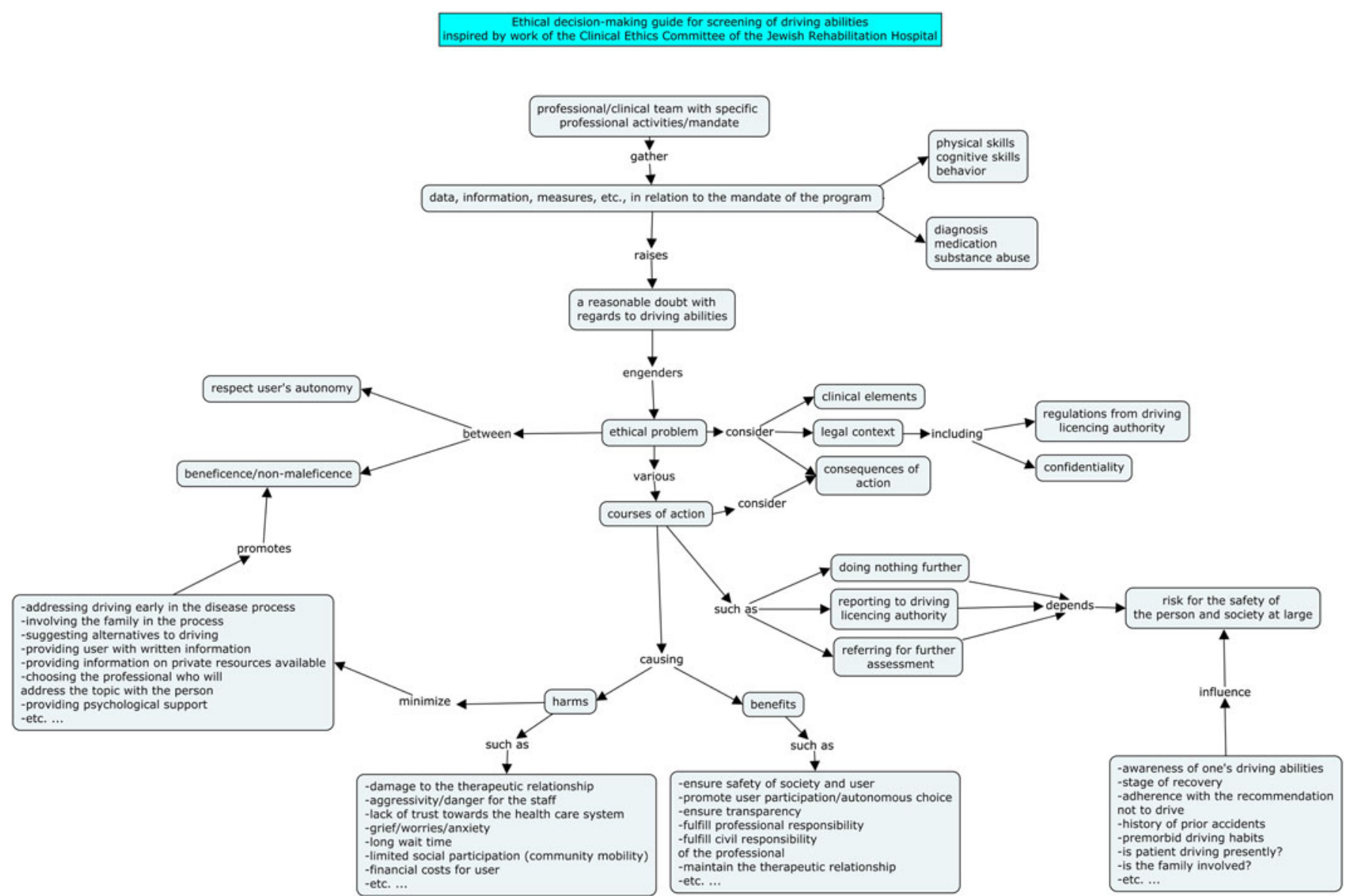

Figure 2: HCP guide to deliberations in difficult driving-related situations (simplification)

Some HCPs may understand their role to be one where they need to report all drivers whom they determine are at a heightened crash risk due to medical or healthrelated changes and may choose to "play it safe" and report any risk, irrespective of how small, thus sometimes causing unnecessary harm. Other HCPs may decide to never report a patient even when they clearly are not safe to drive. However, all HCPs must carefully assess the specific nature of each situation, consider the alternative courses of action, and resort to reporting only when clearly warranted. In instances when reporting is necessary, HCPs should undertake actions to minimize the harm that can result by supporting the patient's emotional needs as well as their need for alternative modes of transportation. With the patient's permission, including their family in the decision process may alleviate some of the negative effects.

The patient's right to confidentiality is an important democratic value, protected by the law and professional codes. Even if a discretionary system is in place, the values supporting confidentiality need to be respected, and a patient's refusal to address driving safety with the family and/or the licensing agency cannot be ignored. Confidentiality must be respected except if there are compelling reasons not to. Because of the important implications associated with decisions to report or not, and in many cases, the lack of evidence supporting these decisions, HCPs should examine each case closely. In some circumstances, identifying a high medical risk to driving is evident and reporting may be the clear choice.

In other situations, there is greater uncertainty. In situations of uncertainty, HCPs must carefully examine the situation to estimate the risk and determine the best course of action, taking into consideration other obligations, objectives, and values. A number of factors should be carefully considered including their relationship with the patient, the method of communicating information and recommendations, possible alternative strategies in addition to reporting, their area of expertise in relation to the particular source of risk, their degree of confidence in the evaluation of risk, and the possibility of strengthening the risk assessment or accessing additional resources. Any measures that can serve to preserve the professional relationship may increase the probability that recommendations are followed and that the potential negative consequences of these steps are reduced. 


\section{Conclusion}

This article has focused on the ethical decision-making that HCPs must address when faced with a potentially unsafe driver. While the issues are complex and there are often no definitive solutions, the ethical principles outlined in this article provide an approach to contemplating the best course of action and can serve to guide decisions in these difficult clinical situations. Further development of accurate measures to provide evidence-based outcomes as well as clear clinical guidelines will assist HCPs to make ethical clinical decisions for their clients.

\section{References}

Anstey, K. J., Wood, J., Lord, S., \& Walker, J. G. (2005). Cognitive, sensory and physical factors enabling driving safety in older adults. Clinical psychology review, 25(1), 45-65.

Appel, J. (2009). Must physicians report impaired driving? Rethinking a duty on a collision course with itself. Journal of Clinical Ethics, 20(3), 136-140.

Asimakopulos, J., Boychuck, Z., Sondergaard, D., Poulin, V., Ménard, I., \& Korner-Bitensky, N. (2012). Assessing executive function in relation to fitness to drive: A review of tools and their ability to predict safe driving. Australian Occupational Therapy Journal, 59(6), 402-427.

Beauchamp, T. L., \& Childress, J. F. (2009). Principles of biomedical ethics. Don Mills, ON: Oxford University Press.

Canadian Medical Association. (2012). CMA driver's guide: Determining medical fitness to operate motor vehicles. Ottawa, ON: Government Printing Office.

CBC News. (2014, April 8) Seniors behind the wheel: Are you concerned? CBC News. Retrieved from http:/ / www.cbc. $\mathrm{ca} /$ news / canada/british-columbia / seniors-behindthe-wheel-are-you-concerned-1.2602924

Dickerson, A. E., Molnar, L. J., Eby, D. W., Adler, G., Bédard, M., Berg-Weger, M., et al. (2007). Transportation and aging: A research agenda for advancing safe mobility. The Gerontologist, 47(5), 578-590.

Eberhard, J. (2008). Older drivers' high per-mile crash involvement: The implications for licensing authorities. Traffic Injury Prevention, 9(4), 284-290.

Fain, M. J. (2003). Should older drivers have to prove that they are able to drive? Archives of Internal Medicine, 163(18), 2126-2128.

Fitten, L. J. (2003). Driver screening for older adults. Archives of Internal Medicine, 163(18), 2129.

Frucht, S., Rogers, J., Greene, P., Gordon, M., \& Fahn, S. (1999). Falling asleep at the wheel: Motor vehicle mishaps in persons taking praimpexole and ropinirole. $\mathrm{Neu}$ rology, 52, 1908-1910.

Heikkila, V. M., Turkka, J., Korpelainen, J., Kallanranta, T., \& Summala, H. (1998). Decreased driving ability in people with Parkinson's disease. Journal of Neurology and Neurosurgery Psychiatry, 64, 325-330.

Hoggarth, P. A., Innes, C. R., Dalrymple-Alford, J. C., \& Jones, R. D. (2013a). Prospective study of healthy older drivers: No increase in crash involvement or traffic citations at 24 months following a failed on-road assessment. Transportation Research Part F: Traffic Psychology and Behaviour, $16,73-80$.

Hoggarth, P. A., Innes, C. R., Dalrymple-Alford, J. C., \& Jones, R. D. (2013b). Predicting on-road assessment pass and fail outcomes in older drivers with cognitive impairment using a battery of computerized sensory-motor and cognitive tests. Journal of the American Geriatrics Society, 61(12), 2192-2198.

Hopewell, C. A. (2002). Driving assessment issues for practicing clinicians. The Journal of Head Trauma Rehabilitation, 17(1), 48-61.

Hunt, M. R., \& Ells, C. (2011). Partners towards autonomy: Risky choices and relational autonomy in rehabilitation care. Disability and Rehabilitation, 33(11), 961-967.

Insurance Institute for Highway Safety. (2008). Older drivers' fatal crashes trend down, Status Report, 43(11). Arlington, VA: Author.

Insurance Institute for Highway Safety. (2014). Fit for the road: Older drivers' crash rates continue to drop, Status Report, 49(1). Arlington, VA: Author.

Iverson, D., Gronseth, G., Reger, M., Classen, S., Dubinsky, R., \& Rizzo, M. (2010). Practice parameter update: Evaluation and management of driving risk in dementia. Report of the Quality Standards Subcommittee of the American Academy of Neurology, Neurology, 74(16), 1316-1324.

Kay, L. G., Bundy, A. C., Clemson, L., Cheal, B., \& Glendenning, T. (2012). Contribution of off-road tests to predicting on-road performance: A critical review of tests. Australian Occupational Therapy Journal, 59(1), 89-97.

Li, G., Braver, E. R., \& Chen, L. H. (2003). Fragility versus excessive crash involvement as determinants of high death rates per vehicle-mile of travel among older drivers. Accident Analysis and Prevention, 35(2), 227-235.

Lord, S., Despres, C., \& Ramadier, T. (2011). When mobility makes sense: A qualitative and longitudinal study of the daily mobility of the elderly. Journal of Environmental Psychology, 31(1), 52-61.

Marottoli, R. A., de Leon, C. F. M., Glass, T. A., Williams, C. S., Cooney, L. M., \& Berkman, L. F. (2000). Consequences of driving cessation decreased out-of-home activity levels. The Journals of Gerontology Series B: Psychological Sciences and Social Sciences, 55(6), S334-S340.

Marottoli, R. A., \& Richardson, E. D. (1998). Confidence in, and self-rating of, driving ability among older drivers. Accident Analysis and Prevention, 30(3), 331-336. 
Marshall, S. C. (2008). The role of reduced fitness to drive due to medical impairments in explaining crashes involving older drivers. Traffic Injury Prevention, 9(4), 291-298.

Murdock, S. (2014). 'Stop driving,' says daughter of woman killed by elderly driver. Huffington Post. Retrieved from http:/ / www.huffingtonpost.com/2014/04/09/doreenlandstra-driver_n_5111264.html

Myers, A. M., Trang, A., \& Crizzle, A. M. (2011). Naturalistic study of winter driving practices by older men and women: Examination of weather, road conditions, trip purposes, and comfort. Canadian Journal on Aging, 30(4), 577-589.

Newbold, K. B., Scott, D. M., Spinney, J. E., Kanaroglou, P., \& Paez, A. (2005). Travel behavior within Canada's older population: A cohort analysis. Journal of Transport Geography, 13(4), 340-351.

Ontario Ministry of Transportation. (2013). Driving handbook. Retrieved from http://www.mto.gov.on.ca/english/ dandv/driver/handbook/section4.2.0.shtml

Organisation for Economic Co-operation Development (OECD). (2001). Ageing and transport: Mobility needs and safety issues. Product Code: 01-RS-03-OECD. Paris, France: Author.

Ott, B. R., Davis, J. D., Papandonatos, G. D., Hewitt, S., Festa, E. K., Heindel, W. C. et al. (2013). Assessment of drivingrelated skills prediction of unsafe driving in older adults in the office setting. Journal of the American Geriatrics Society, 61(7), 1164-1169.

Oxley, J., \& Whelan, M. (2008). It cannot be all about safety: The benefits of prolonged mobility. Traffic Injury Prevention, 9(4), 367-378.

Pachana, N. A., \& Petriwskyj, A. M. (2006). Assessment of insight and self-awareness in older drivers. Clinical Gerontologist, 30(1), 23-38.

Ragland, D. R., Satariano, W. A., \& MacLeod, K. E. (2005). Driving cessation and increased depressive symptoms. The Journals of Gerontology Series A: Biological Sciences and Medical Sciences, 60(3), 399-403.

Statutes of Quebec. (2014, c. C-24.2). Regulation respecting access to driving a road vehicle in connection with the health of drivers Highway Safety Code. Retrieved from Société de l'assurance automobile du Québec (SAAQ), http: / / www2.publicationsduquebec.gouv.qc.ca/
dynamicSearch $/$ telecharge.php?type $=2 \&$ file $=\% 2 \mathrm{~F} \% 2 \mathrm{FC}$ 24_2\%2FC24_2R8_A.htm

Schrag, A. (2005). Driving in Parkinson's disease. Journal of Neurology and Neurosurgery Psychiatry, 76, 159.

Scott, D. M., Newbold, K. B., Spinney, J. E., Mercado, R., Perez, A., \& Kanaroglou, P. S. (2009). New insights into senior travel behavior: The Canadian experience. Growth and Change, 40(1), 140-168.

Sims, J., Rouse-Watson, S., Schattner, P., Beveridge, A., \& Jones, K. (2012). To drive or not to drive: Assessment dilemmas for GPs. International journal of family medicine (Article ID 41712), 1-6.

Sivak, M. (2013). Female drivers in the United States, 1963-2010: From a minority to a majority? Traffic Injury Prevention, 14(3), 259-260.

Société de l'assurance automobile du Québec (SAAQ). (2014). Road safety is for all ages (ISBN No. 978-2-550-70883-4). Montréal, QC: Bibliothèque nationale du Québec.

Sohlberg, M. (2000). Assessing and managing unawareness of self. Seminars in Speech and Language, 21(2), 135-152.

Solomon, R., Chamberlain, E., \& Chiodo, S. (2011). Silence may not be golden: A review of health professionals' statutory obligations to report unfit drivers. Health Law Review, 19(2), 5-16.

Statistics Canada. (2008). Décès dus aux accidents de véhicules à moteur, 1979 à 2004. In Rapport sur la santé. Ottawa, ON: Ramage-Morin, P. L.

Turcotte, M. (2012). Profile of seniors' transportation habits. Ottawa, ON: Statistics Canada.

Unsworth, C. A., Lovell, R. K., Terrington, N. S., \& Thomas, S. A. (2005). Review of tests contributing to the occupational therapy off-road driver assessment. Australian Occupational Therapy Journal, 52(1), 57-74.

Vrkljan, B. H., McGrath, C. E., \& Letts, L. J. (2011). Assessment tools for evaluating fitness to drive: A critical appraisal of evidence. Canadian Journal of Occupational Therapy, 78(2), 80-96.

Wood, J. M., Worringham, C., Kerr, G., Mallon, K., \& Silburn, P. (2005). Quantitative assessment of driving performance in Parkinson's disease. Journal of Neurology and Neurosurgery Psychiatry, 76, 176-180. 